\title{
Parkinson's Disease in the Very Old - Clinicopathological Observations
}

\author{
Rajput $\mathrm{AH}^{*}$ and Rajput $\mathrm{EF}$ \\ Saskatchewan Movement Disorders Program, University of Saskatchewan/Saskatoon Health Region, Saskatoon, Canada
}

*Corresponding author: Rajput AH, Division of Neurology, Royal University Hospital, 103 Hospital Drive, Saskatoon, Saskatchewan S7N 0W8, Canada, Fax: (306) 844-1506, Tel: (306) 844-1412, E-mail: ali.rajput@saskatoonhealthregion.ca

Citation: Rajput AH, Rajput EF (2017) Parkinson's Disease in the Very Old - Clinicopathological Observations. J Neurosci Neuropsyc 1: 104. doi: 10.18875/2577-7890.1.104

Article history: Received: 07 July 2017, Accepted: 29 September 2017, Published: 02 October 2017

\begin{abstract}
Background: The incidence of Parkinson syndrome (PS) increases dramatically after age 80 years. As the number of the very old ( $>80$ years) is rising in the population, the number of PS cases would increase. In the general population the most common variant of PS is the Parkinson's disease (PD). PD is characterized by marked loss of substantia nigra neurons and Lewy Body (LB) inclusions. All the pathological variants of PS in the elderly however remain unknown. The objective of this study was to determine the frequency of different PS variants and their course in the elderly individuals.

Results: We studied 30 PS cases that had onset age $>80$ years and came to autopsy between 1968 and 2015. Autopsy study was performed by certified neuropathologists. 21 of 30 cases had PD as the only movement disorder, two more patients had PD plus another movement disorder.

Detailed analysis of 21 PD only cases revealed that mode of onset was the upper limb tremor, which is similar to the PD cases of all ages. They all improved on levodopa, as do most PD patients. Compared to younger onset PD cases, there was higher incidence of stroke and dementia in this age group. But stroke was not the cause of PD. The motor disability was more rapid than in the younger onset PD cases. We recommend that all elderly persons that have a clinical diagnosis of PS or PD should be treated with levodopa.
\end{abstract}

Keywords: Very old; Parkinsonism; Parkinson's disease; Octogenarian

\section{Introduction}

Two hundred years ago (1817), James Parkinson wrote "An Essay on the Shaking Palsy" [1]. Subsequent studies lead to greater understanding of that clinical entity. Shaking which attracted the attention of James Parkinson is not present in every patient. The term "Palsy" usually implies motor weakness. There is no paralysis in this syndrome but there is an impairment of function primarily due to motor slowing. Therefore the term "Shaking Palsy" is no longer used.

Subsequent studies have identified several different pathological entities which produce a similar clinical picture [2,3]. As well, some drugs notably dopamine (DA) receptor blocking agents can produce the same clinical features. These cases are known as Drug-Induced Parkinsonism (DIP) [4]. The DIP has no histological changes in the brain [4]. In recent years, the incidence of DIP has declined because of a more widespread use of new atypical neuroleptic [5]. A major epidemic of encephalitis lethargica between 1915 and 1930 resulted in a large number of cases with parkinsonian features, known as Post-Encephalitic Parkinsonism (PEP). There have been no new cases of PEP since mid-1960's [6,7].

The term Parkinson syndrome (PS) applies to all cases with similar clinical manifestation regardless of the cause. The main motor clinical features are: bradykinesia, rigidity and tremor [2,8-15]. Two of those three are needed to make a clinical diagnosis of PS $[8,9,12]$. Most PS cases have neurodegenerative pathology $[2,3,16]$. The term Parkinson's disease (PD) is reserved for cases with marked substantia nigra neuronal loss (Figure 1) and LB neuronal inclusions (Figure 2). Although in clinical practice, the diagnosis of PS and PD each is based on the motor findings noted above, definite diagnosis of PS variants is based on pathological findings, and errors in clinical diagnosis of PD have been reported by several studies [2,8,11-15]. Other common degenerative variants include progressive supranuclear palsy (PSP), multiple system atrophy (MSA) and corticobasal degenerative disease (CBD). 
PSP is clinically characterized by onset with balance and gait difficulty. These cases do not have prominent tremor. Their body posture is erect. Gaze palsy - typically vertical gaze, is characteristic. Pathology is characterized by widespread neuronal loss and tau positive neurofibrillary tangle [3].

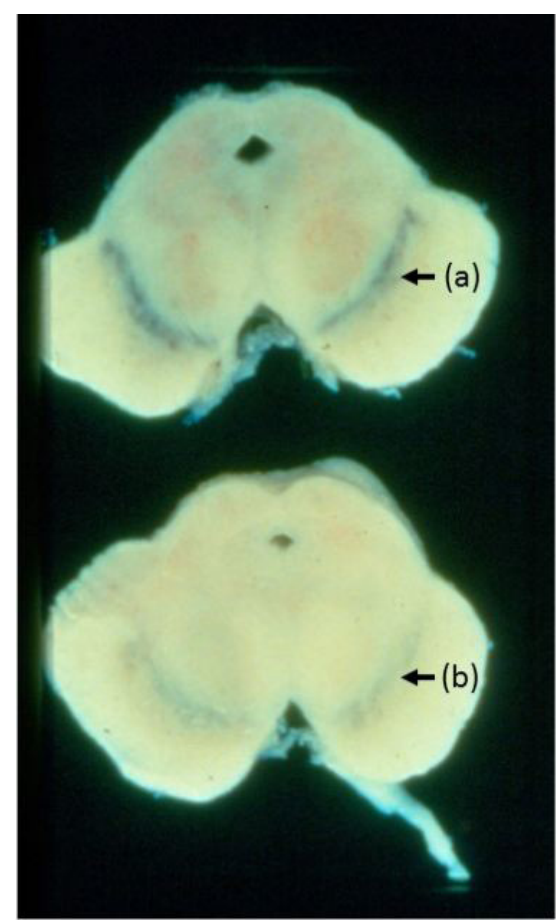

Figure 1: Mid brain gross section: (a) shows normal substantia nigra, (b) loss of pigmented cells in the substantia nigra in Parkinson's disease

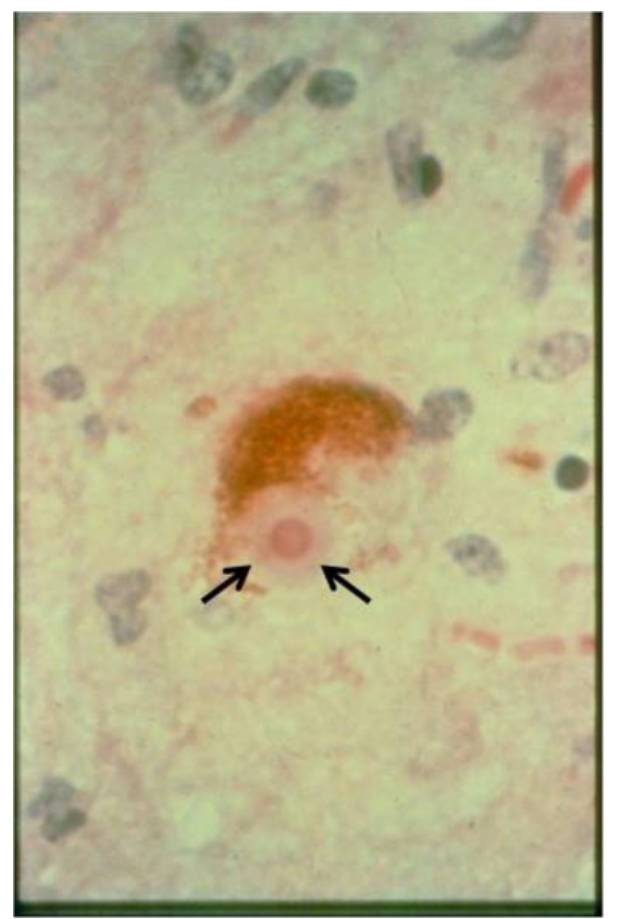

Figure 2: Arrows point to H\&E stained Lewy body inclusion characterized by concentric circles with darker central and lighter peripheral circle in a pigmented neuron

MSA is characterized by early gait and balance difficulty or autonomic dysfunction - postural hypotension, erectile dysfunction, etc. These patients usually do not have prominent tremor. There is generalized flexed posture. Cerebellar and corticospinal tract findings are common. Pathology is characterized by widespread neuronal loss and alphasynuclein positive glial inclusion [3].

CBD is characterized unilateral onset of dystonia, behavioral changes, apraxia and stimulus sensitive myoclonus. Pathology is characterized by cortical atrophy, tau positive inclusions and swollen neurons [3].

Old age is the best known risk for developing PS and the PD [17-22]. Individuals over the age of 80 years have been classified as "very old" [20]. The incidence of PS (new cases) in the very old (80 to 89) year age population is more than double that in the 65 
to 69 year age group [21]. In recent years, the proportion of the elderly population has increased at a faster rate than the growth of the general population $[17,21,22]$. Some experts have predicted rising future healthcare needs for PS cases [22].

The pathological basis of PS and the clinical profile in the autopsy confirmed $>80$ year age onset individuals remain to be determined.

The objective of this study was to identify different variants of PS and their course in autopsy verified cases with onset $>80$ years age [23].

\section{Material and Methods}

The patients included in this study were all evaluated at the Movement Disorder Clinic Saskatchewan (MDCS). Figure 3 shows a flow chart of the Saskatchewan Movement Disorders Program (SMDP) and the MDCS.
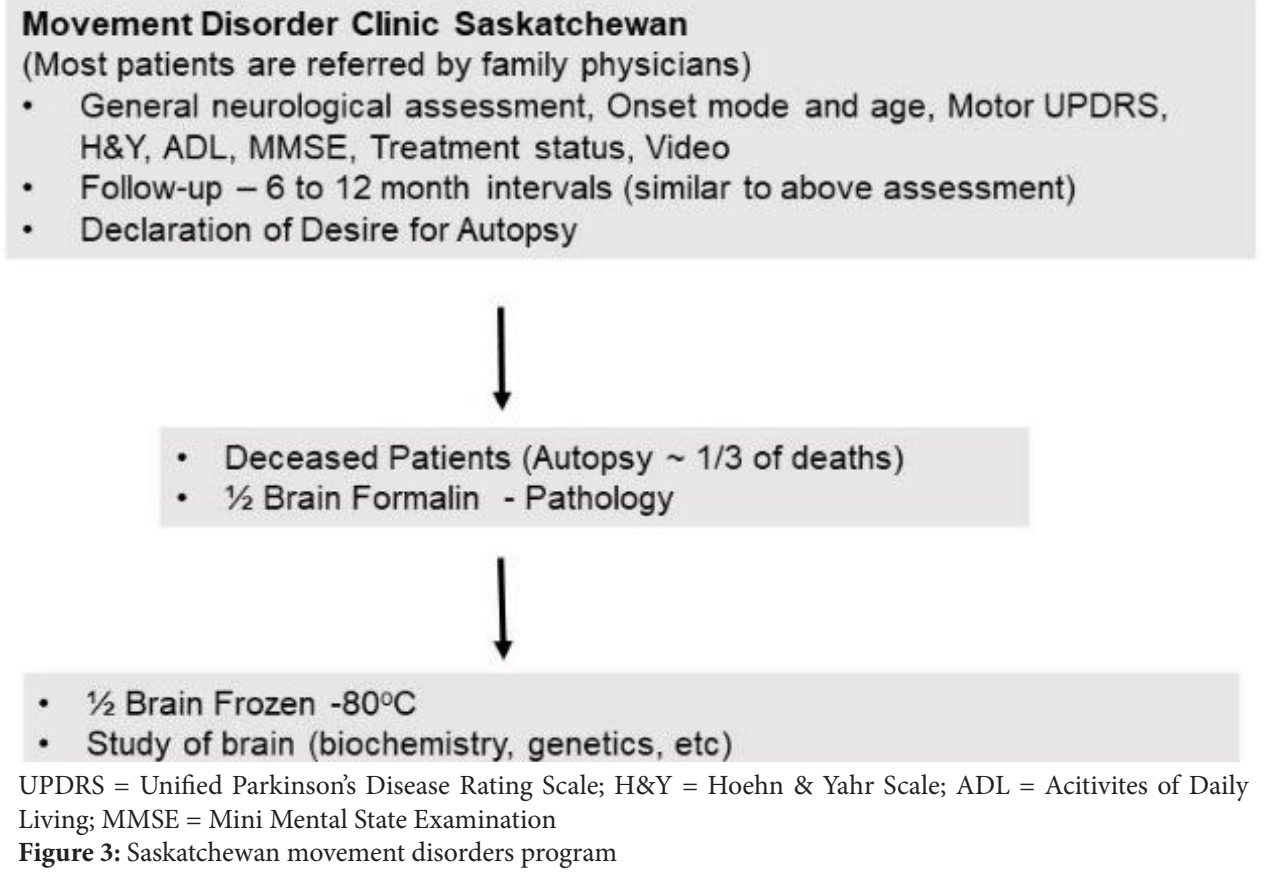

The SMDP and the MDCS have been conducted uninterrupted since 1968 by the same one or two neurologists [24]. Most patients are referred to the MDCS by family physicians.

All Saskatchewan residents carry general tax funded provincial healthcare insurance. There is no direct cost to patients to attend the MDCS. Thus there is an equal access to this clinic for every resident in the province. As a rule, the patients are seen on a first come basis. The patients are typically followed at the MDCS at 6 to 12 month interval. Between clinic visits the patients have free telephone access to the Movement Disorders neurologists. At an opportune time patients are asked to express desire for autopsy. There is no cost to the family or estate of the patient for autopsy study [24]. The patient is assured that this declaration would not impact ongoing care at the MDCS. Demographics, age, sex, mode and age of PS onset, treatment status, adverse effects, motor Unified Parkinson's Disease Scale (UPDRS) and Hoehn \& Yahr (H\&Y) stage are assessed at baseline, and a video is made on every consenting subject $[25,26]$. At each visit the patient is assessed by the same one or two Movement Disorders neurologists and clinical information and assessments pertinent to PS are made [24].

All patients seen at the MDCS between 1968 and 2015 that had diagnosis of PS with onset $>80$ years who came to autopsy were included in this study $[23,24]$.

Some of our patients did not have formal education. Diagnosis of dementia was therefore based on documented cognitive function decline considering age and education of the individual. In recent years, mini mental state examination (MMSE) is performed at baseline and annually.

The two Movement Disorders neurologists are on 24/7 (unpaid) call to arrange autopsy within 24 hours of death. Approximately $30 \%$ of deceased cases come to autopsy. Immediately after autopsy the brain is divided at midline - one-half is submitted for pathology studies and the other half is frozen at $-80^{\circ} \mathrm{C}$ for further studies. A board certified neuropathologist produces detailed pathology report, which is provided to the family with an offer to discuss the significance of findings.

Original clinical data, videos, frozen half brains, remnants of formalin tissue, paraffin blocks and slides are preserved in our laboratory (Figure 4). Final diagnosis of the PS variants is made by the treating neurologist considering all the clinical and pathology information [24]. 


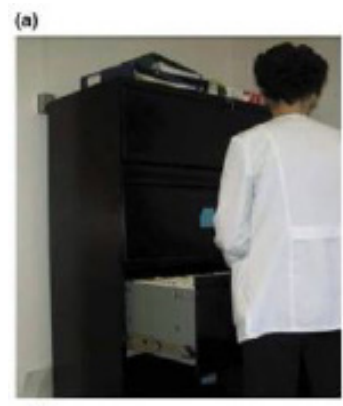

(d)

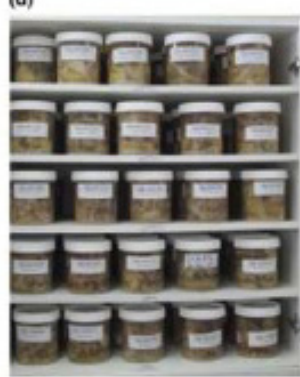

(b)
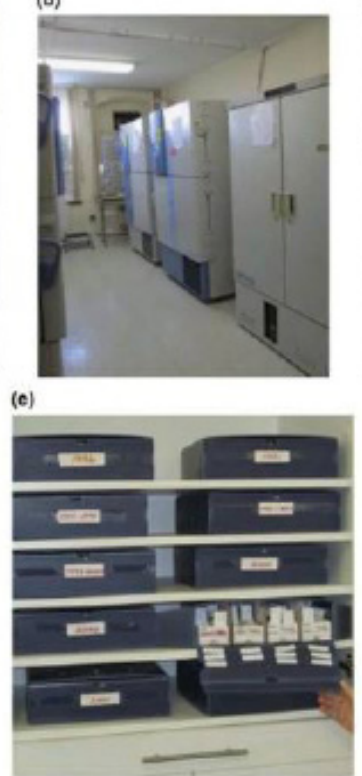

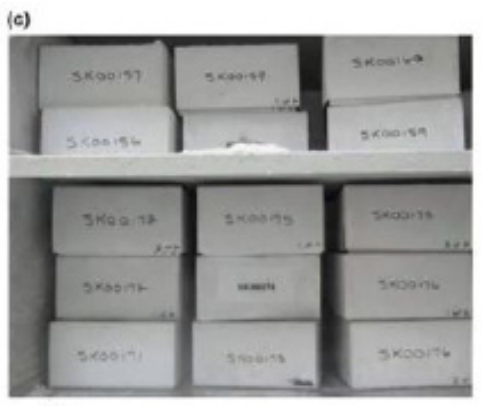

(f)

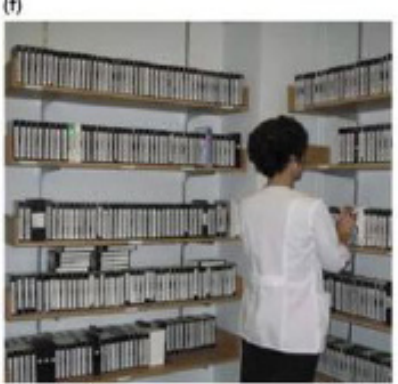

Figure 4: To date - 549 autopsies performed on our own patients (a) Filing cabinet containing hard copies of patient clinical records. (b) - $80{ }^{\circ} \mathrm{C}$ freezers; Currently there are nine freezers (c) Cardboard boxes, each containing half-frozen brain from a patient. (d) Formalin-fixed remains of the brain tissue after pathology has been completed. (e) paraffin blocks and glass slides stored in our laboratory. (f) Video library (approx. 6000 patient videos so far)

\section{Results}

392 patients seen at MDCS who had clinical diagnosis of PS came to autopsy during the study interval (1968 - 2015). 80\% of those had PD [27]. Thirty cases including 15 males that had clinical diagnosis of PS with onset age $>80$ years and autopsy verification of the underlying pathology were included in this study [23]. The DIP cases were excluded, but all other patients who fulfilled the study criteria were included [23]. The mean age of onset was 82.6 (range 80 to 87 ) years.

Table 1 shows demographic and diagnosis in the 30 patients. In 21 cases PD was the only movement disorder (PDO). In one patient the final diagnosis was PD and essential tremor (ET) and in one more patient the final diagnosis was PD plus PSP. All patients were treated with LD at some point. All PD only cases and some other PS cases improved on LD [23].

Detailed analysis was focused on the 21 PDO cases. Five of those 21 (24\%) cases also had stroke. The stroke did not involve substantia nigra in any of these cases. In those patients that had stroke prior to clinical manifestation of PS, the parkinsonian features manifested first on the side contralateral to the stroke related clinical deficit. Thus stroke was not the cause of PD in any case. Table 1 shows that three additional PS cases had stroke which may have contributed to some of their clinical features.

\begin{tabular}{|c|c|c|c|c|}
\hline $\begin{array}{c}\text { Case } \\
\text { Number }\end{array}$ & Sex & $\begin{array}{c}\text { Onset Age } \\
\text { Age at Death) }\end{array}$ & Onset & Final Diagnosis \\
\hline 1 & M & $87(96)$ & Gait & PD + Stroke + AD \\
\hline 2 & F & $80(89)$ & Tremor, UL & PD \\
\hline 3 & F & $83(94)$ & Tremor, UL & PD \\
\hline 4 & M & $87(95)$ & Not Known & PD + Stroke + AD \\
\hline 5 & F & $82(92)$ & Tremor, UL & PD \\
\hline 6 & F & $80(89)$ & Bradykinesia & PD \\
\hline 7 & F & $83(94)$ & Tremor, UL & PD \\
\hline 8 & M & $81(95)$ & Tremor, UL & PD \\
\hline 9 & M & $85(93)$ & Gait & PD - PDD \\
\hline 10 & F & $81(85)$ & Bradykinesia & PD \\
\hline 11 & F & $83(90)$ & Tremor, UL & PD \\
\hline 12 & M & $84(91)$ & Tremor, UL & PD \\
\hline 13 & M & $80(89)$ & Tremor, UL & PD - PDD \\
\hline 14 & F & $81(92)$ & Tremor, UL & PD - PDD \\
\hline 15 & M & $81(88)$ & Tremor, LL & PD \\
\hline 16 & F & $86(92)$ & Tremor, UL & PD - PDD \\
\hline 17 & M & $84(86)$ & Tremor, UL & \\
\hline
\end{tabular}




\begin{tabular}{|c|c|c|c|c|}
\hline $\begin{array}{c}\text { Case } \\
\text { Number }\end{array}$ & Sex & $\begin{array}{c}\text { Onset Age } \\
\text { (Age at Death) }\end{array}$ & Onset & Final Diagnosis \\
\hline 18 & M & $84(90)$ & Tremor, UL & PD \\
\hline 19 & F & $81(93)$ & Gait & PD + Stroke \\
\hline 20 & F & $82(93)$ & Tremor, UL & PD + Stroke \\
\hline 21 & F & $83(91)$ & Tremor, LL & PD + Stroke \\
\hline 22 & F & ET at 60, PS at $85(94)$ & ET, (UL PS) & ET + PD \\
\hline 23 & M & $80(87)$ & Gait & PD + PSP \\
\hline 24 & M & $84(93)$ & Tremor, UL & Multiple Stroke \\
\hline 25 & M & $83(90)$ & Tremor, UL & ET + RT \\
\hline 26 & M & $82(86)$ & Tremor, UL & PS + BGC + Stroke \\
\hline 27 & F & $82(90)$ & Tremor, UL \& LL & PSP + Stroke \\
\hline 28 & M & ET at 60, PS at $85(89)$ & ET + Gait & ET + PSP \\
\hline 29 & M & $80(88)$ & Gait & PSP \\
\hline 30 & F & $80(87)$ & Bradykinesia & PS + SN Neuronal loss \\
\hline
\end{tabular}

DYS = Dyskinesia, WO = Wearing Off, OO = On Off, UL = Upper limb, LL = Lower Limb, ET $=$ Essential Tremor, PD = Parkinson's Disease, $\mathrm{PSP}=$ Progressive Supranuclear Palsy, PS = Parkinson Syndrome, AD = Alzheimer's Disease, BGC = Basal Ganglia Calcification, $\mathrm{SN}=$ Substantia Nigra, Gait $=$ Gait Difficulty, $\mathrm{PDD}=$ Parkinson’s Disease Dementia

Table 1: All PS Cases - Onset Age and Final Diagnosis $(\mathrm{N}=30)$

Table 2 shows major prognostic indicators in the 21 PDO cases. Dementia was observed in eight of 19 (42\%) of the PDO cases where that diagnosis could be established. Four patients had dementia consequent to cortical LB pathology (PDD). Two PD patients had additional Alzheimer's disease. Pathological basis of dementia could not be established in two cases.

\begin{tabular}{|c|c|c|c|c|c|}
\hline $\begin{array}{c}\text { Case } \\
\text { Number }\end{array}$ & $\begin{array}{c}\text { Improvement on } \\
\text { Levodopa }\end{array}$ & DYS, WO, OO & Dementia & $\begin{array}{l}\text { History of } \\
\text { Stroke }\end{array}$ & Survival \\
\hline 1 & Unknown & DYS & Yes (AD) & Yes & $9 \mathrm{yrs}$ \\
\hline 2 & Yes & None & No & No & 9 yrs \\
\hline 3 & Yes & DYS & No & No & $11 \mathrm{yrs}$ \\
\hline 4 & Unknown & None & Yes (AD) & Yes & 8 yrs \\
\hline 5 & Yes & DYS, WO & No & No & 10 Yrs \\
\hline 6 & Yes & None & No & No & $9 \mathrm{yrs}$ \\
\hline 7 & Yes & DYS & No & No & $11 \mathrm{yrs}$ \\
\hline 8 & Yes & DYS & No & No & $14 \mathrm{yrs}$ \\
\hline 9 & Yes & DYS & Yes (PDD) & No & $8 \mathrm{yrs}$ \\
\hline 10 & Yes & None & No & No & 4 yrs \\
\hline 11 & Yes & None & No & No & $7 \mathrm{yrs}$ \\
\hline 12 & Yes & DYS & Yes & No & $7 \mathrm{yrs}$ \\
\hline 13 & Yes & WO & Yes & No & 9 yrs \\
\hline 14 & Yes & WO & Yes (PDD) & No & $11 \mathrm{yrs}$ \\
\hline 15 & Unknown & None & Yes (PDD) & No & $7 \mathrm{yrs}$ \\
\hline 16 & Yes & None & No & No & $6 \mathrm{yrs}$ \\
\hline 17 & & None & Yes (PDD) & No & 2 yrs \\
\hline 18 & Yes & None & Unknown & No & $6 \mathrm{yrs}$ \\
\hline 19 & Yes & DYS, WO & No & Yes & $12 \mathrm{yrs}$ \\
\hline 20 & Mild & None & No & Yes & $11 \mathrm{yrs}$ \\
\hline 21 & $\begin{array}{l}\text { Did Not Tolerate } \\
\text { Adequate Dose }\end{array}$ & NA & Unknown & Yes & 8 yrs \\
\hline
\end{tabular}

DYS $=$ Dyskinesia, $\mathrm{WO}=$ Wearing Off, $\mathrm{OO}=$ On Off, $\mathrm{AD}=$ Alzheimer's Disease, $\mathrm{PDD}=$ Parkinson's Disease Dementia Table 2: Major indicators of prognosis in the elderly Parkinson's Disease as the only pathology cases $(\mathrm{N}=21)$

Figure 5 shows the duration of symptoms until reaching Stages 3, 4 and 5 H\&Y where the information was available $[25,26]$. Three patients reached Stage 3 after median 8 years. Eight cases reached Stage 4 after median 6 years, and eight cases reached Stage 5 after median 6.5 years. The mean survival after onset in the 21 PDO cases was 8.5 years (median 8 years). All the PDO cases that tolerated adequate dose of LD improved on the drug (Table 2) [16]. 


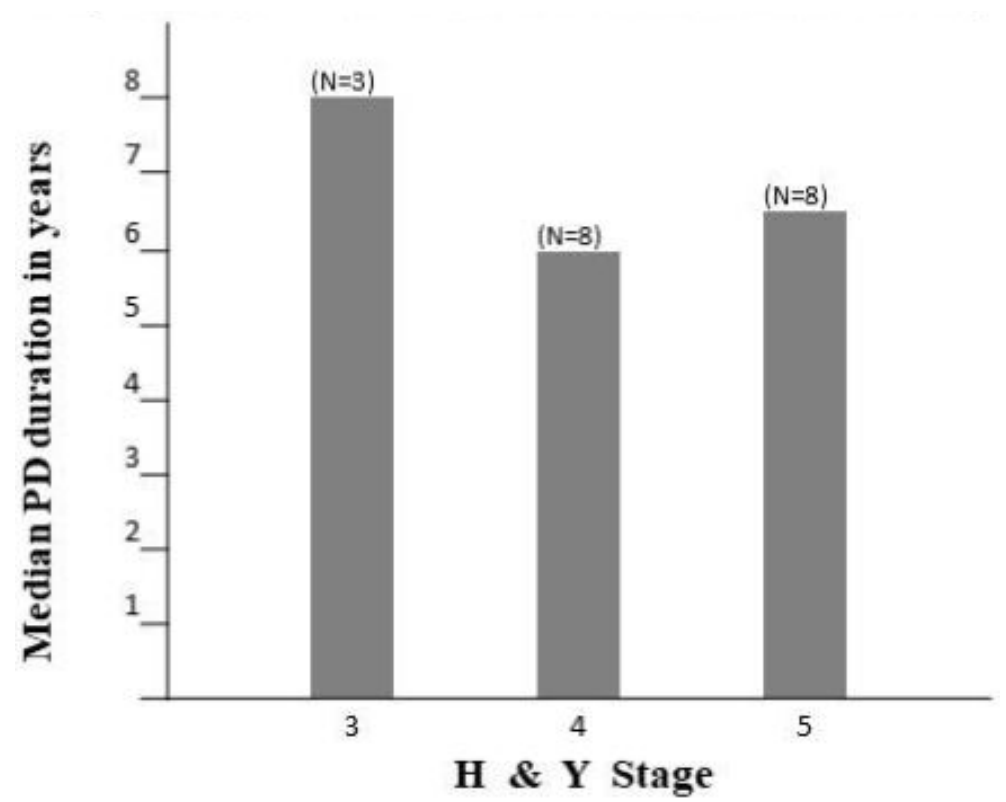

Figure 5: Median duration from onset to reaching high level of disability in 21 PD only cases (Number of PD cases where data available)

\section{Discussion}

The cause of PS in the very old remains unknown. Old age is the best known risk for PD and PS. Many otherwise normal elderly are known to have some features resembling Parkinsonism [18]. However, old age or premature aging is not the cause of PD. As in the PD, there is some loss of striatal DA in old age but the sub-regional pattern of DA loss characteristic of PD is not present in the normal elderly [28].

Several different pathological variants of PS have been reported and new genetic variants are being identified $[2,3,29,30]$. One clinical study reported that PS variants in the elderly are different from those in the general population [31]. In one study when DIP cases were excluded, 62\% of all PS cases had PD [31]. But when 80 to 99 year onset PS was considered, only 23\% had PD, but pathological findings were not reported in that study [31]. Therefore, the exact nature of PS pathology was not established. By contrast our study includes longitudinal clinical follow-up and autopsy verification of PS variants in the very old individuals [23].

As in the general population the most common PS variants in the very old age onset cases was the PD. 21 (70\%) cases had PDO and two other patients that had PD plus another disorder thus 23 of the 30 (77\%) had PD pathology. Those numbers are similar to reported in other autopsied series $[2,8,16,27,29]$. The second most common PS variant in our cases was the PSP. That is similar to another autopsy report [32]. As reported by others, these PSP cases did not manifest ophthalmoplegia which made the clinical diagnosis difficult [32,33]. In our study there were no cases of MSA or CBD - the other two well-known degenerative variants of PS in our study.

Since the largest proportion of the cases in our study had PDO, we compared the clinical profile of these cases with the reported literature. There are several similarities and some significant differences: the onset was the upper limb tremor in the PDO cases (Table 1 ), which is similar to that reported in all onset age inclusive PD cases $[9,34,35]$. As in our study, one previous clinicopathological report observed that the pathological findings in the older subjects are similar to those in the younger subjects [36]. Levodopa (LD) is the most effective symptomatic drug for PD and PD cases that tolerate adequate dose of LD improve on the drug [16]. All PDO cases in this study improved on LD. As well, some cases with other forms of PS improved on LD [23]. Similar observations have been reported in all age inclusive variants of PS [16].

There are some notable differences in this age group compared to the general PD population. Where it could be ascertained, dementia was evident in eight of the 19 (42\%) PDO cases after mean 8.5 years of onset. That figure is significantly higher than the $25 \%$ dementia reported in all-inclusive PD cases after 10 years of onset [37]. Thus dementia evolved earlier in the very old age onset PD cases. The most common cause was the PD associated dementia (PDD).

Stroke is more common in the elderly persons. That would apply to the PD patients as well. Five of 21 (24\%) of PDO cases had stroke. Stroke is considered as possible contributor to Alzheimer's disease [38]. However no such association could be established in PDO cases. One epidemiological study which included general population, ET and PD cases, found that the incidence of stroke was similar in the three groups [39]. One autopsy study reported 13\% vascular disease in all forms of PS [32]. They did not specify the stroke in PD as we have done. Our observation indicates that stroke is more common in $>$ than 80 year onset PD cases.

We considered the relationship of stroke to the PD. None of the PDO cases had stroke involving the substantia nigra which is primary site of pathology in PD. As well, none of the patients manifested PD on the same side as was the motor deficit due to 
prior stroke. These indicate that PD is not consequent to stroke in these cases. However stroke was sole basis of PS in one case and contributed to PS features in two others (Table 1).

Hoehn \& Yahr scale is a well-known measure of disease severity [25,26]. Previous studies have reported on progression of PD using H\&Y scale in autopsy verified PD cases [40,41]. Stage 4 is characterized by severe disability and Stage 5.0 cases are bedridden. Figure 5 show's that eight cases reached Stage 4 after a median six years of onset. By contrast, one study where all PD cases were included, Stage 4 disability was reached after a mean 12.8 years [40]. Similarly reaching Stage 5.0 was accelerated in the very old PDO cases. Eight of our cases reached Stage 5 after median 6.5 years of onset contrasted to a mean 14.8 years in all-inclusive PD in a previous study [40]. Thus the PD motor disability is accelerated in the very old onset cases. The elderly more often have other health problems. That may contribute to more rapid functional decline in these cases. We cannot separate that component from the disability due to $\mathrm{PD}$ alone. Functional neuroimaging studies of patients with similar duration of PD show, that there is more pronounced reduction in the striatal DA levels in the older age onset compared to the younger onset cases [9]. Together these indicate that higher comorbidity notwithstanding; there are biological reasons for a more rapid functional decline in the very old PD cases.

As expected, the survival after PD onset in the very old is shorter than in the younger patients.

\section{Some special considerations in the very old age onset PS cases}

The first step in diagnosis of PD is, to establish that the patient has PS. That requires presence of two of three - bradykinesia, rigidity and resting tremor $[8,9,12]$. The second step is to determine clinically that the patient has PD and not another PS variant $[12,13]$. Diagnosis of PD in the PS case is based on the absence of other findings such as autonomic dysfunction, corticospinal tract deficit, ophthalmoplegia, cerebellar signs, etc. which are part of other PS variants [12,13].

Comorbidity and age related physical changes that mimic Parkinsonism need special consideration in the elderly. Gait and balance impairment are part of normal aging in some individuals $[18,42,43]$. The elderly are more likely to have lower limb ailments such as arthritis, joint replacement, etc. resulting in gait and balance difficulty. Although some studies have considered gait and balance as a significant early sign in PD, most experts exclude that as a requirement for PD diagnosis [12]. As such, it is not a reliable indicator of PD.

Some of the three cardinal motor features - bradykinesia, rigidity and tremor may be present in normal elderly. In one study, 5.8\% cases had Bradykinesia [18]. Bradykinesia is characterized by slowing of motor function which may be confused as normal aging. In the normal aging the slowing down is always symmetrical whereas in PD it is often asymmetrical [43]. Bradykinesia is tested by rapid repetitive movements such as pronation/supination of the forearm, tapping index finger against the thumb, tapping heel on the floor, or tapping front of the foot on the floor. In true Bradykinesia, there is progressive decrease in the amplitude of movement and it may have eventual arrest. In the normal elderly there will be slowing of alternating movements but the progressive amplitude decline which is a feature of PS is not present.

The second major feature of PS is the rigidity. It is characterized by increased resistance to passive movement at a joint. It can be assessed at the wrist, elbow or shoulder in the upper limbs and the knee in the lower limbs. In one study $0.76 \%$ normal elderly had "rigidity" [18]. The passive movement should be performed slowly to appreciate the rigidity. In contrast, the pyramidal tract disease induced "spasticity" is velocity dependent, where the rapid passive movement produces a catch and then release. Rigidity is evident as increased tone throughout the passive movement. When there is a rachety character to the rigidity it is called cogwheel rigidity. The tone is normal and symmetrical in the normal elderly. Re-enforcement, such as, testing the tone at the right wrist and asking the patient to tap his left foot while the passive movement is in progress can uncover mild rigidity coinciding with the reinforcement effort [43].

Paratonia or gegenhalten is another confounder in the elderly. It is characterized by intermittent, irregular and often unpredictable resistance to passive movement. The resistance may increase as the movement progresses. Sometimes there is excessive facilitation of the intended passive movement, even when the patient is instructed, not to do so. This happens in situations when the patient does not understand the instructions and is unable to cooperate with tone testing [43].

If there is focal pain producing pathology such as arthritis or injury, there would be resistance to passive movements and thus may be misinterpreted as rigidity. It is important to ensure that there is no focal cause which produces pain or mechanical restriction to passive movement [43].

Another confounder for cogwheeling in the presence of coarse tremor. In patients with prominent ET, with reinforcement there may be intermittent change in tone. That could be interpreted as cogwheel rigidity. In such a case, stop the passive movement when you feel cog wheeling. If it is consequent to the tremor the abnormal movement will persist but in true cogwheeling rigidity the involuntary movement will cease [43].

Tremor is the third major feature of PS. Typically PD tremor is present at rest. One study reported "tremor" in $1.2 \%$ of the normal elderly. They did not specify behavioral context of the tremor. There are several metabolic diseases and drugs that can produce tremor, and the elderly use more drugs than younger subjects [44]. For a resting tremor test, have the patient lie in supine position 
on the examining table with arms fully supported against gravity and ankles fully supported so they are not overhanging the table. You may put the patient under stress by having the individual count backwards from 100 and observe the limbs for tremor. Resting tremor is not a part of normal aging and is the most reliable indicator of PS in the elderly subject.

Our study of 30 autopsied very old age onset cases shows that the most common PS variant is the PD in this age group. The mode of onset as the upper limb tremor is similar to that in the general PD population. Like the all-inclusive PD patients the PDO cases improve on LD. Dementia and stroke are more common, and the progression of motor disability is accelerated in this age group of cases. Since all elderly PD patients and some other forms of PS benefit from LD, they should be tried on the drug once a clinical diagnosis of PD or PS is made.

\section{Acknowledgment}

We are grateful to Dr. A. Rajput for allowing the use of his patient data, to Ms. L. Beatty and Ms. M. Cowper for the production of manuscript.

\section{References}

1. Parkinson J (2002) An essay on the shaking palsy. 1817. J Neuropsychiatry Clin Neurosci 14: 223-36.

2. Marsden CD, Fahn S (1987) The Pathology of Parkinsonism. In: Movement Disorders (2nd edn). Willey Online Library, London 124-65.

3. Pfeiffer RF, Wszolek ZK, Ebadi M (2005) The Neuropathology of Parkinson's Disease and Other Parkinsonian Disorders In: Parkinson's Disease. CRC Press, Florida 401-18.

4. Shuaib UA, Rajput AH, Robinson CA, Rajput A (2016) Neuroleptic-induced Parkinsonism: Clinicopathological study. Mov Disord 31: 360-5.

5. Savica R, Grossardt BR, Bower JH, Ahlskog JE, Mielke MM, et al. (2017) Incidence and time trends of drug-induced parkinsonism: A 30-year population-based study. Mov Disord 32: 227-234.

6. Duvoisin RC, Yahr MD (1965) Encephalitis and Parkinsonism. Arch Neurol 12: 227-39.

7. Rajput AH, Offord KP, Beard CM, Kurland LT (1984) Epidemiology of parkinsonism: incidence, classification, and mortality. Ann Neurol 16: 278-82.

8. Rajput AH, Rozdilsky B, Rajput A (1991) Accuracy of clinical diagnosis in parkinsonism--a prospective study. Can J Neurol Sci 18: 275-8.

9. Pagano G, Ferrara N, Brooks DJ, Pavese N (2016) Age at onset and Parkinson disease phenotype. Neurology 86: 1400-7.

10. Reinoso G, Allen JC, Au WL, Seah SH, Tay KY, et al. (2015) Clinical evolution of Parkinson's disease and prognostic factors affecting motor progression: 9-year follow-up study. Eur J Neurol 22: 457-63.

11. Duvoisin RC, Golbe LI (1989) Toward a definition of Parkinson's disease. Neurology 39: 746.

12. Gelb DJ, Oliver E, Gilman S (1999) Diagnostic criteria for Parkinson disease. Arch Neurol 56: 33-9.

13. Postuma RB, Berg D, Stern M, Poewe W, Olanow CW, et al. (2015) MDS clinical diagnostic criteria for Parkinson’s disease. Mov Disord 30: $1591-601$.

14. Adler CH, Beach TG, Hentz JG, Shill HA, Caviness JN, et al. (2014) Low clinical diagnostic accuracy of early vs advanced Parkinson disease: clinicopathologic study. Neurology 83: 406-12.

15. Hughes AJ, Daniel SE, Kilford L, Lees AJ (1992) Accuracy of clinical diagnosis of idiopathic Parkinson's disease: a clinico-pathological study of 100 cases. J Neurol Neurosurg Psychiatry 55: 181-4.

16. Rajput AH, Rozdilsky B, Rajput A, Ang L (1990) Levodopa efficacy and pathological basis of Parkinson syndrome. Clin Neuropharmacol 13: 553-8.

17. Savica R, Grossardt BR, Bower JH, Ahlskog JE, Rocca WA (2016) Time Trends in the Incidence of Parkinson Disease. JAMA Neurol 73: 981-9.

18. Buchman AS, Leurgans SE, Yu L, Wilson RS, Lim AS, et al. (2016) Incident parkinsonism in older adults without Parkinson disease. Neurology 87: 1036-44.

19. Findley LJ, Capildeo R (1984) Neurochemical Basis of Parkinsonian Tremor In: Movement Disorders: Tremor. Springer, Basingstoke, London 305-19.

20. Diederich NJ, Moore CG, Leurgans SE, Chmura TA, Goetz CG (2003) Parkinson disease with old-age onset: a comparative study with subjects with middle-age onset. Arch Neurol 60: 529-33.

21. Elbaz A, Bower JH, Maraganore DM, McDonnell SK, Peterson BJ, et al. (2002) Risk tables for parkinsonism and Parkinson’s disease. J Clin Epidemiol 55: 25-31.

22. Chen H (2016) Are We Ready for a Potential Increase in Parkinson Incidence? JAMA Neurol 73: 919-21.

23. Rajput AH, Rajput EF (2017) Octogenarian parkinsonism - Clinicopathological observations. Parkinsonism Relat Disord 37: 50-57.

24. Rajput AH, Rajput A (2015) Saskatchewan Movement Disorders Program. Can J Neurol Sci 42: 74-87.

25. Fahn S, Marsden CD, Calne DB, Goldstein M (1987) Unified Parkinson's disease rating scale In: Recent Developments in Parkinson's Disease (2 ${ }^{\text {nd }}$ edn). UPDRS Development Committee, USA 153-305.

26. Hoehn MM, Yahr MD (1967) Parkinsonism: onset, progression and mortality. Neurology 17: 427-42.

27. Rajput AH, Ferguson LW, Robinson CA, Guella I, Farrer MJ, et al. (2016) Conjugal parkinsonism - Clinical, pathology and genetic study. No evidence of person-to-person transmission. Parkinsonism Relat Disord 31: 87-90.

28. Kish SJ, Shannak K, Rajput A, Deck JH, Hornykiewicz O (1992) Aging produces a specific pattern of striatal dopamine loss: implications for the etiology of idiopathic Parkinson's disease. J Neurochem 58: 642-8.

29. Paulus W, Jellinger K (1991) The neuropathologic basis of different clinical subgroups of Parkinson's disease. J Neuropathol Exp Neurol 50: 743-55.

30. Gasser T, Hardy J, Mizuno Y (2011) Milestones in PD genetics. Mov Disord 26: 1042-8.

31. Bower JH, Maraganore DM, McDonnell SK, Rocca WA (1999) Incidence and distribution of parkinsonism in Olmsted County, Minnesota, 1976-1990. Neurology 52: 1214-20.

32. Bower JH, Dickson DW, Taylor L, Maraganore DM, Rocca WA (2002) Clinical correlates of the pathology underlying parkinsonism: a population perspective. Mov Disord 17: 910-6.

33. Birdi S, Rajput AH, Fenton M, Donat JR, Rozdilsky B, et al. (2002) Progressive supranuclear palsy diagnosis and confounding features: report on 16 autopsied cases. Mov Disord 17: 1255-64. 
34. Rajput AH, Pahwa R, Pahwa P, Rajput A (1993) Prognostic significance of the onset mode in parkinsonism. Neurology 43: 829-30.

35. Uitti RJ, Baba Y, Wszolek ZK, Putzke DJ (2005) Defining the Parkinson's disease phenotype: initial symptoms and baseline characteristics in a clinical cohort. Parkinsonism Relat Disord 11: 139-45.

36. Gibb WR, Lees AJ (1988) A comparison of clinical and pathological features of young- and old-onset Parkinson's disease. Neurology 38: 1402-6.

37. Hely MA, Reid WG, Adena MA, Halliday GM, Morris JG (2008) The Sydney multicenter study of Parkinson's disease: the inevitability of dementia at 20 years. Mov Disord 23: 837-44.

38. Pereira E, Silva M, Peixoto B (2016) Prevalence, incidence and characteriation of neurocognitive impairment in acute coronary syndrome. A systematic review and meta-analysis. J Neurosci Neuropsyc 1: 102.

39. Nataraj A, Rajput AH (2005) Parkinson’s disease, stroke, and related epidemiology. Mov Disord 20: 1476-80.

40. Rajput AH, Voll A, Rajput ML, Robinson CA, Rajput A (2009) Course in Parkinson disease subtypes: A 39-year clinicopathologic study. Neurology 73: 206-12.

41. Ferguson LW, Rajput AH, Rajput A (2016) Early-onset vs. Late-onset Parkinson's disease: A Clinical-pathological Study. Can J Neurol Sci 43: 113-9.

42. Stern MB, Koller WC (1993) Parkinsonism, Aging and Gait Apraxia In: Parkinsonian Syndromes. Wiley Online Library, New York 511-32.

43. Koller WC, Melamed E (2007) Old age and Parkinson's disease In: Handbook of Clinical Neurology. Science Direct 427-44.

44. Desai TH, Rajput AH, Desai HB (1990) Use and abuse of drugs in the elderly. Prog Neuropsychopharmacol Biol Psychiatry 14: 779-84. 